\title{
Calculation analysis of sustained casing pressure in gas wells
}

\author{
Zhu Hongjun ${ }^{1}$, Lin Yuanhua ${ }^{1 *}$, Zeng Dezhi ${ }^{2}$, Zhang Deping ${ }^{2}$ and Wang Feng ${ }^{2}$ \\ ${ }^{1}$ State Key Laboratory of Oil and Gas Reservoir Geology and Exploitation, Southwest Petroleum University, Chengdu, \\ Sichuan 610500, China \\ ${ }^{2}$ Jilin Field Company, PetroChina, Songyuan, Jilin 138000, China
}

(C) China University of Petroleum (Beijing) and Springer-Verlag Berlin Heidelberg 2012

\begin{abstract}
Sustained casing pressure (SCP) in gas wells brings a serious threat to worker safety and environmental protection. According to geological conditions, wellbore structure and cement data of gas wells in the Sichuan-Chongqing region, China, the position, time, environmental condition and the value of SCP have been analyzed. On this basis, the shape of the pressure bleed-down plot and pressure buildup plot were diagnosed and the mechanism of SCP has been clarified. Based on generalized annular Darcy percolation theory and gas-liquid two-phase fluid dynamics theory, a coupled mathematical model of gas migration in a cemented annulus with a mud column above the cement has been developed. The volume of gas migrated in the annulus and the value of SCP changing with time in a gas well in Sichuan have been calculated by this model. Calculation results coincided well with the actual field data, which provide some reference for the following security evaluation and solution measures of SCP.
\end{abstract}

Key words: Sustained casing pressure, gas migration, coupled mathematic model, gas well

\section{Introduction}

After well completion, pressure in all of the casing strings should be zero if the well is flowing at steady state conditions, but due to initial thermal expansion effects a small volume of fluids has to be bled through a needle valve in order for the casing pressure to fall to atmospheric pressure (Bourgoyne et al, 1999). If the casing pressure builds up when the needle valve is closed, the casing is said to exhibit sustained casing pressure (SCP).

Well cement problems such as small cracks or channels can result in gas migration and lead to SCP at casing heads (Dusseault et al, 2000; Kinik and Wojtanowicz, 2011). In some cases, the casing pressure can reach dangerously high values. SCP in acid gas wells brings a serious threat to worker safety and environmental protection. Therefore, we need to better understand the reason for gas migration and the mechanism of SCP.

11,498 casing strings in 8,122 wells in the Gulf of Mexico (GOM) have been reported with SCP (Bourgoyne et al, 1998). Studies funded by the MMS (US Minerals Management Service) have been done by some investigators (Wojtanowicz et al, 2001; Xu, 2002; Xu and Wojtanowicz, $2001 ; 2003)$. Based on previous research, MMS regulations (30 CFR 250.517) require elimination of SCP and grant departures permitting operation of wells with small SCP problems. However, wells with approved departure must be

* Corresponding author. email: yhlin28@163.com

Received May 6, 2011 frequently tested in order to monitor and control the severity of SCP. These tests include pressure bleed-down and pressure buildup.

The diagnostic test calls for bleeding the pressure to zero through a 0.5 -in needle valve and recording the casing pressure. Then the value of initial pressure bled down during the test can be obtained from the recorded data. Recorded pressures from other annuli would indicate whether there is communication between different casings in the well. However, no analytical method has been developed for quantitatively analyzing these tests. The needle valve is closed to initiate pressure buildup and the pressure recorded for 24 hours. The rate of pressure buildup could provide additional information about the size and possibly the location of the leak. But there is still no method for interpreting the test. Furthermore, testing of SCP is mostly qualitative and limited to arbitrary criteria. Such information is insufficient for operators to quantitatively analyze SCP problems. Thus there is a need for improved analysis that could provide more information.

The work presented here focuses on the mechanism of SCP and a coupled mathematical model of gas migration in a cemented annulus with a mud column in a gas well, which provide some reference for the following security evaluation and solution measures of SCP.

\section{Field data analysis}

SCP is a universal problem occurred in gas wells in China. The field data are casing pressure records provided 
by various operators from 13 gas wells, which mainly come from the Longgang, Luojiazhai, Puguang, Zhongba and Moxi gas fields in Sichuan-Chongqing region in China.

\subsection{Statistical analysis of SCP data}

Of the 13 gas wells, 12 show SCP problems (shown in Table 1) and all the production casing strings exhibit SCP. The percentage of SCP presenting in intermediate casing strings, surface casing strings and conductor casing strings are $90 \%, 83.3 \%$ and $7.7 \%$, respectively.

Fig. 1 shows the frequency of SCP for different casings. Production casings and intermediate casings present more serious SCP. Fifty percent of the production casings and 56 percent of the intermediate casings have SCP of less than 10 $\mathrm{MPa}$. And 80 percent of the surface casings have SCP of less than $5 \mathrm{MPa}$. The SCP magnitude in conductor strings is the lowest, all have SCP of less than $5 \mathrm{MPa}$.

For instance, the productive reservoir of A gas field is in the Feixianguan Formation. After well completion, the gas production rate of the A1 well reached $114 \times 10^{4} \mathrm{~m}^{3} / \mathrm{d}$. However, the casing pressure in the production casing string is $43.5 \mathrm{MPa}$, which indicates serious gas migration in the annulus. The location of the mud surface in the annulus is at a depth about $200 \mathrm{~m}$. The possible reasons leading to SCP are a poor cementing job, pressure fluctuation, and tubing leak. In some cases, the tubing leak even presents above the mud surface. The production casing pressure in the A2 well is $23 \mathrm{MPa}$, and the intermediate casing pressure is $8.4 \mathrm{MPa}$. Intermediate casing pressure in the A3 well is $12 \mathrm{MPa}$. A major cause of the SCP problem in the two wells, besides poor quality of cement, is casing leakage.

Table 1 SCP occurrence in various casing strings

\begin{tabular}{|c|c|c|c|c|c|c|}
\hline \multirow{2}{*}{ Well $^{\#}$} & \multicolumn{2}{|c|}{ Production casing } & \multicolumn{2}{|c|}{ Intermediate casing } & \multirow{2}{*}{$\begin{array}{c}\text { Surface casing } \\
133 / 8^{\prime \prime}\end{array}$} & \multirow{2}{*}{$\begin{array}{c}\text { Conductor } \\
20^{\prime \prime}\end{array}$} \\
\hline & $51 / 2^{\prime \prime}$ & $7^{\prime \prime}$ & $95 / 8^{\prime \prime}$ & $97 / 8^{\prime \prime}$ & & \\
\hline A1 & & $\mathrm{Y}$ & NA & & NA & $\mathrm{N}$ \\
\hline A2 & & Y & $\mathrm{Y}$ & & NA & $\mathrm{N}$ \\
\hline A3 & & NA & $\mathrm{Y}$ & & NA & $\mathrm{N}$ \\
\hline B1 & & $\mathrm{Y}$ & & $\mathrm{Y}$ & $\mathrm{Y}$ & $\mathrm{N}$ \\
\hline B2 & & $\mathrm{Y}$ & & Y & $\mathrm{Y}$ & $\mathrm{N}$ \\
\hline B3 & & $\mathrm{Y}$ & & Y & Y & $\mathrm{N}$ \\
\hline B4 & & $\mathrm{Y}$ & & $\mathrm{Y}$ & $\mathrm{Y}$ & $\mathrm{N}$ \\
\hline $\mathrm{C} 1$ & $\mathrm{Y}$ & & $\mathrm{Y}$ & & $\mathrm{Y}$ & $\mathrm{Y}$ \\
\hline $\mathrm{C} 2$ & & NA & & $\mathrm{Y}$ & NA & $\mathrm{N}$ \\
\hline D1 & & $\mathrm{Y}$ & NA & & NA & $\mathrm{N}$ \\
\hline D2 & & $\mathrm{Y}$ & NA & & NA & $\mathrm{N}$ \\
\hline E1 & & Y & & Y & NA & $\mathrm{N}$ \\
\hline E2 & & NA & $\mathrm{N}$ & & $\mathrm{N}$ & $\mathrm{N}$ \\
\hline Total & 1 & 9 & 3 & 6 & 5 & 1 \\
\hline$P_{\mathrm{SCP}} \%$ & & & & & 83.3 & 7.7 \\
\hline
\end{tabular}

Notes: Y-SCP problem; N-no SCP problem; NA-data not available.

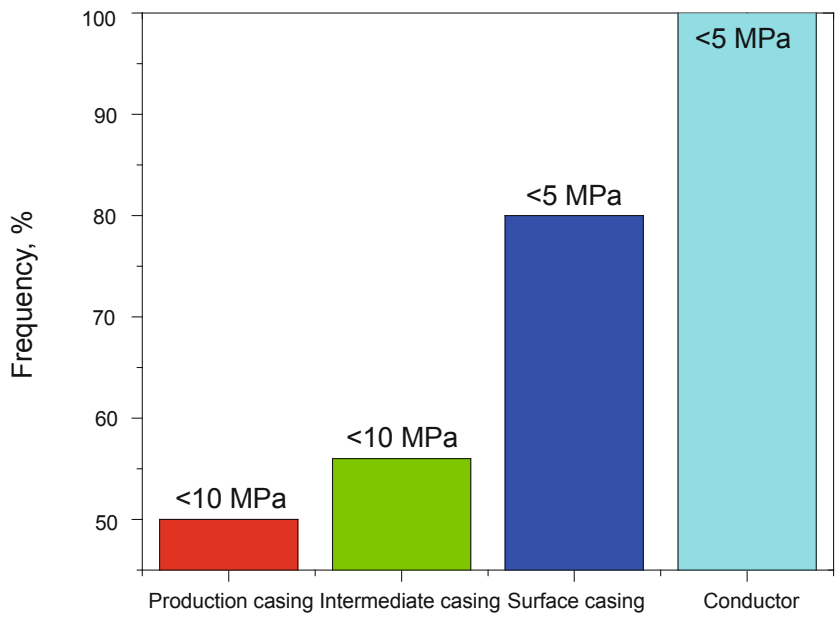

Fig. 1 Frequency of SCP for different casings

\subsection{SCP typical patterns}

Five typical response patterns (Xu, 2002; Milanovic and Smith, 2005) could be concluded from the field data of 13 gas wells, which include two SCP bleed-down patterns and three SCP buildup patterns:

- Instant bleed-down pattern

- Long bleed-down pattern

- Normal buildup pattern

- S-shape buildup pattern

- Incomplete buildup pattern

The bleed-down pattern depends on the opening of the needle valve controlled by operators and the amount of fluids bled from the casing annulus. If the needle valve is opened wide to bleed a small amount of gas and liquid from the casing annulus, the casing pressure would drop to 0 in a very short time, named as instant bleed-down pattern. On the other hand, if operators manipulate the needle valve to minimize the removal of fluids, the duration of bleed-down would be prolonged by the operation, so the casing pressure may not decrease to 0 over the duration of the bleed-down test. It is the other pattern, the long bleed-down pattern. The two bleeddown patterns are shown in Figs. 2 and 3.

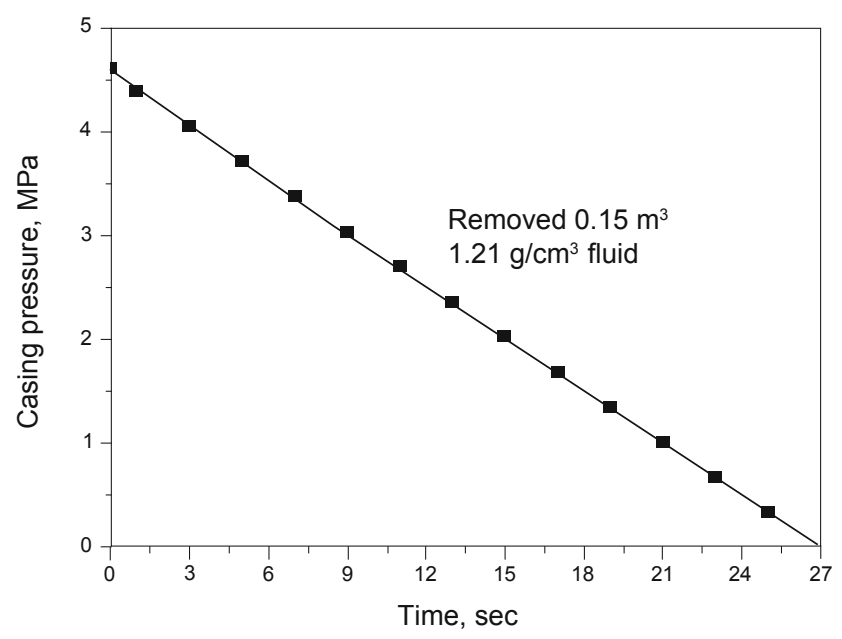

Fig. 2 Instant bleed-down pattern 


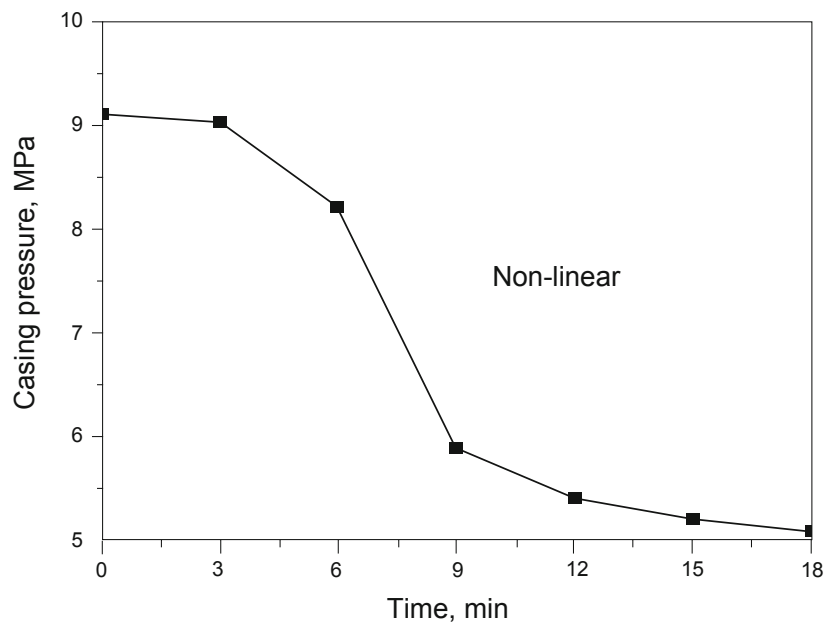

Fig. 3 Long bleed-down pattern

As shown in Figs. 4, 5 and 6, we can see three buildup patterns, which depend on operating conditions such as the magnitude of gas migration, the duration of bleed-down, and the mud weight. After the bleed-down, a normal buildup pattern is observed when a quick initial pressure increase is followed with a transition period of gradual increase until it comes to pressure stabilization. The stabilized casing pressure depends on the mud weight and gas-source formation pressure. The transition period is determined by the magnitude of gas migration in the cement and mud column. If there is almost no gas left in the mud column after bleeddown, there would be no obvious increase in the casing pressure until the first pulse of gas reaches the casing head. Then the casing pressure will increase gradually and finally stabilize. This is the S-shape buildup pattern. An incomplete buildup pattern is noted where no late-time stabilization is apparent in the testing interval (usually 24 hours) and the initial casing pressure increase in the early time is relatively low.

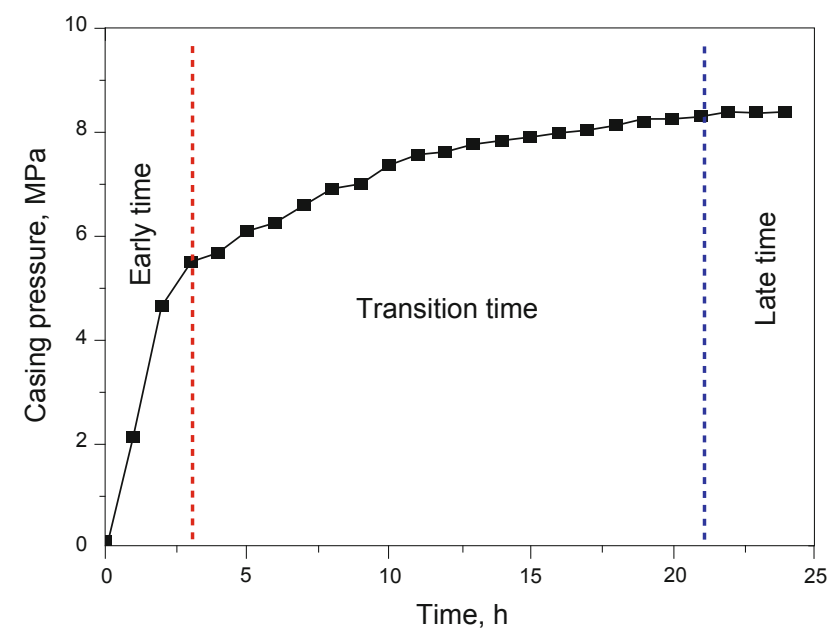

Fig. 4 Normal buildup pattern

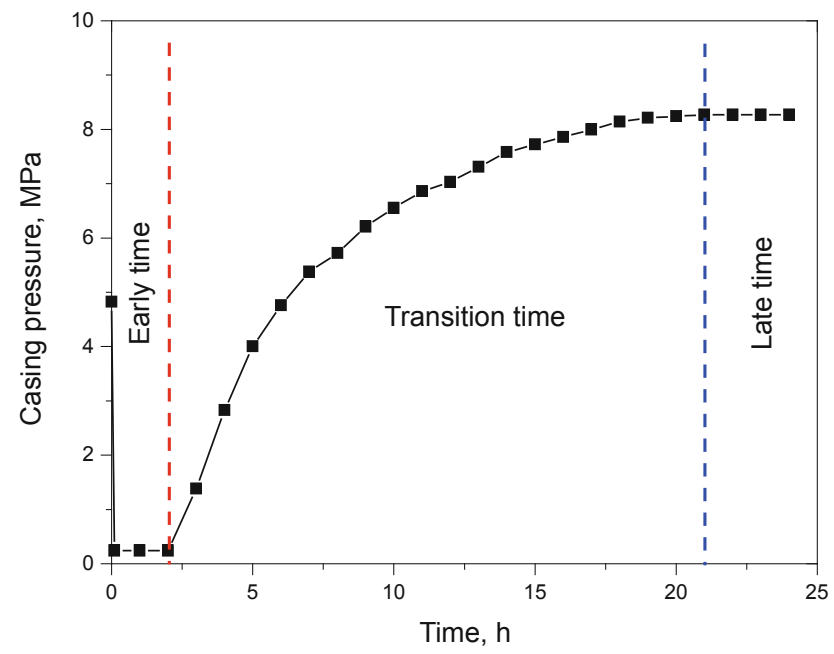

Fig. 5 S-shape buildup pattern

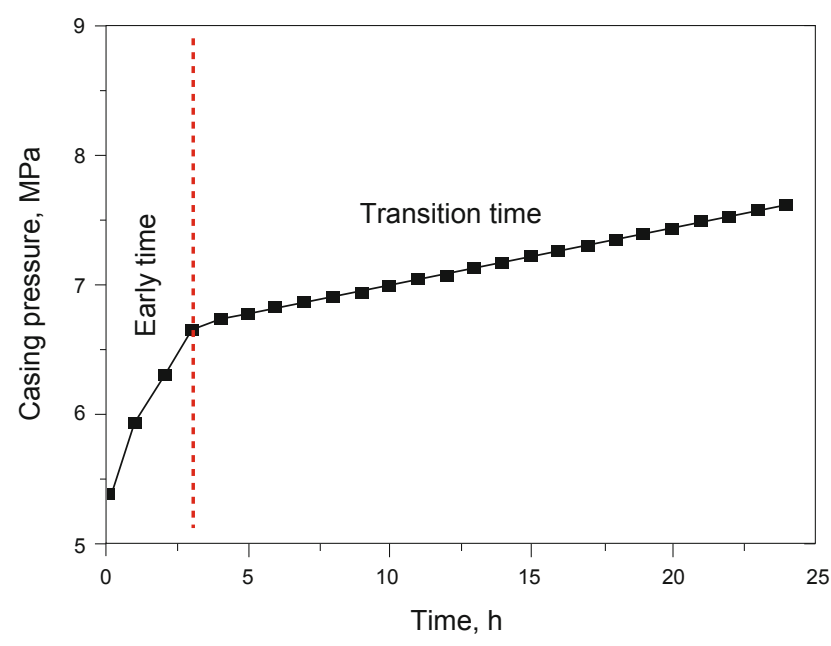

Fig. 6 Incomplete buildup pattern

\section{Mechanism of SCP}

Gas wells are composed of many layers of casing strings, which constitute several annuli. According to the location, the annulus from inside to outside can be named "A" annulus, "B" annulus, "C" annulus, and so forth (Anders et al, 2006). As shown in Fig. 7, "A" annulus represents the annulus between the tube and production casing. "B" annulus represents the annulus between production casing and adjacent intermediate casing. The rest can be obtained by analogy.

As shown in Fig. 8, two possible configurations of the cement column in the annulus are common: cemented to the surface or a mud column above the cement. A gas cap may be present above the mud column. In wells cemented to the surface, gas migration can be considered as a one-dimensional flow through a medium of some conductivity (Nishikawa, 1999). After bleed-down, the buildup behavior is controlled by cement properties, such as permeability and porosity, and by the gas formation pressure. While in wells with a mud 
column above the cement, gas migration occurs in two stages. Firstly, gas flow follows Darcy's Law in the cement column. Then gas rises as bubbles through stagnant non-Newtonian drilling fluids, in which the gas migration is affected by the characteristics of mud and the status of the top gas cap.

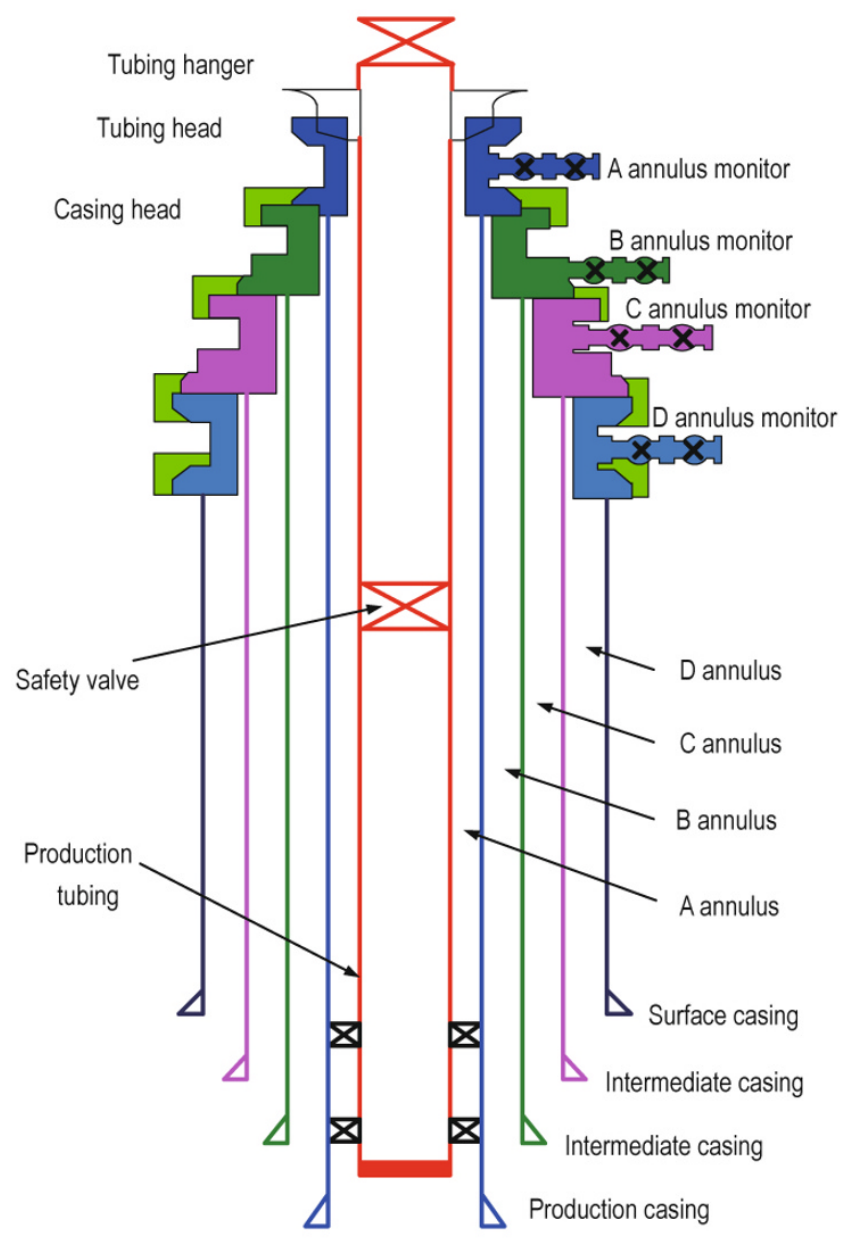

Fig. 7 Annulus schematic drawing
From Fig. 9, we can see that there are several reasons for casing pressure buildups such as thermal expansion, tubular mechanical failures, and gas migration (Nishikawa and Wojtanowicz, 2001; Duan and Wojtanowicz, 2005). The SCP caused by thermal expansion can be eliminated after bleeddown. And disabled tubing or casing strings can be replaced by the new ones. While SCP resulting from gas migration would rebuild after bleed-down.

An SCP problem in different annuli may have different reasons. For A annulus, a possible reason for SCP can be seen from Fig. 10. For the external annulus such as $\mathrm{B}$ or $\mathrm{C}$ annulus, the possible way leading to SCP is shown in Fig. 11.

\section{Coupled mathematical model}

Although there are two possible configurations of the cement column in the annulus, we focus our attention on a coupled mathematical model of gas migration in a cemented annulus with a mud column, which includes gas migration in the cement column. As shown in Fig. 12, gas sequentially flows through cement and mud. Finally it either accumulates at the gas chamber when the needle valve is closed, or evacuates from the chamber when the needle valve is open. In following sections, the mathematical model for this situation will be built.

\subsection{Gas migration in cement}

Gas migration in a cement column can be considered as a one-dimensional flow through a medium having some conductivity, which related with the cement properties, interface pressure, interface flow rate, gas formation pressure, and elapsed time. The following assumptions were made for developing the mathematical model. Firstly, the gas formation pressure is constant because the permeability of the gas zone is much higher than that of the cement. Secondly, the pseudopressure is used. Finally, gas is vented out from the well at a small constant rate at the end of bleed-down. Then with a constant flow rate $q_{n}$ during the $n$-th period, the

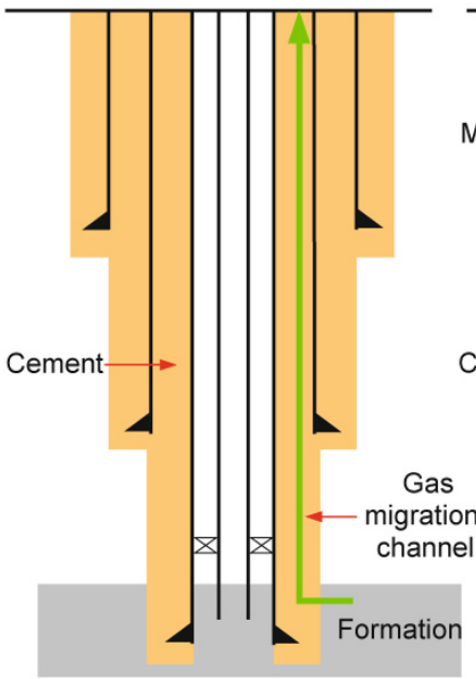

(a) Annulus cemented to the surface

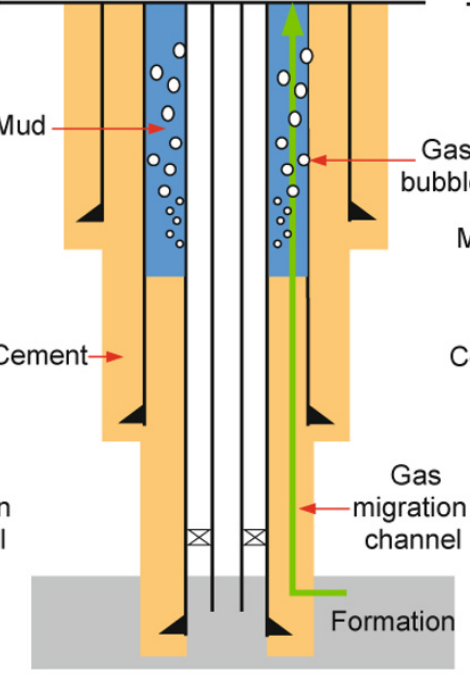

(b) Annulus with a mud column above cement

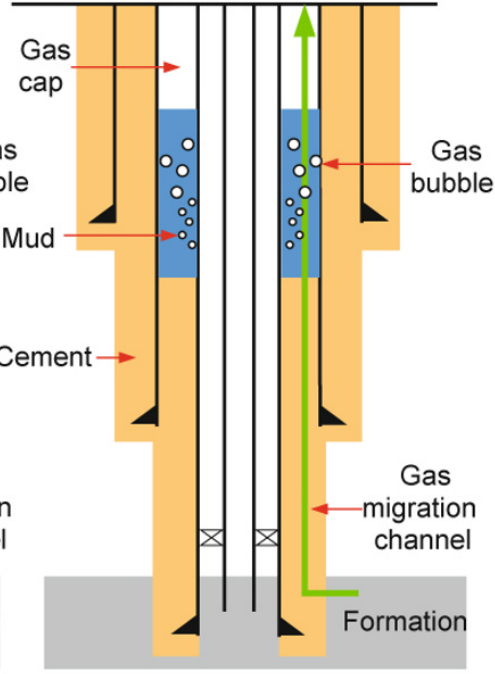

(c) Annulus with a gas cap above mud column

Fig. 8 Configurations of the cement column in the annulus 


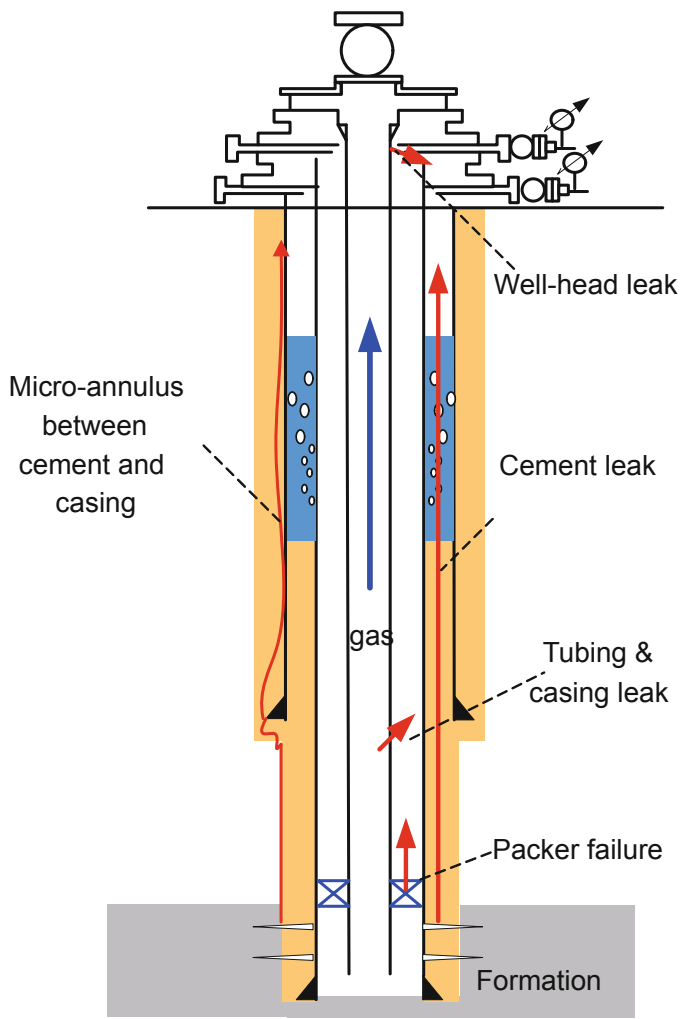

Fig. 9 Possible reasons leading to SCP

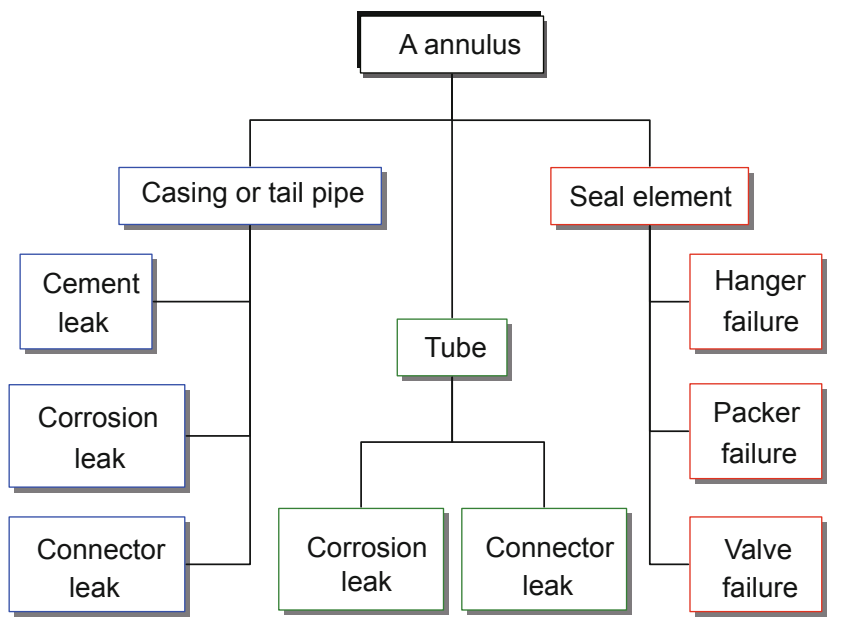

Fig. 10 Possible causes of SCP in the A annulus

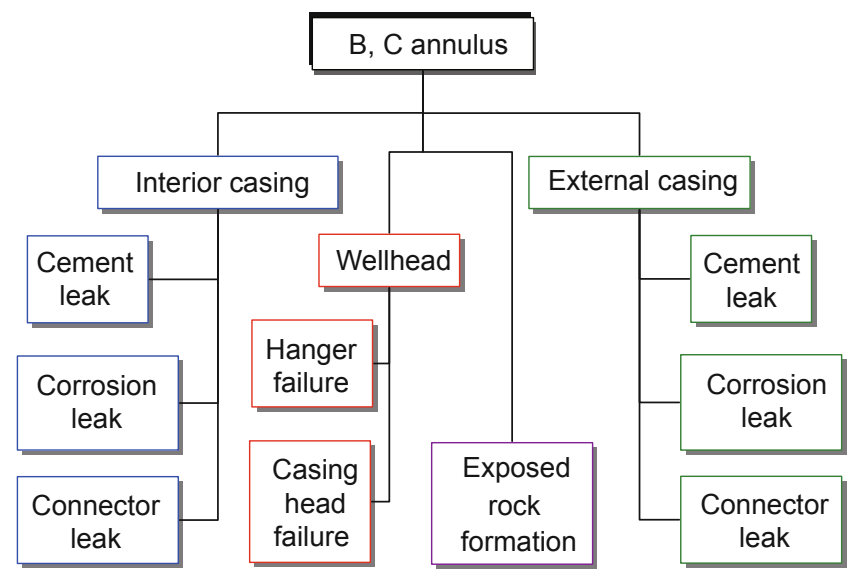

Fig. 11 Possible faults leading to $\mathrm{SCP}$ in the $\mathrm{B}$ or $\mathrm{C}$ annulus

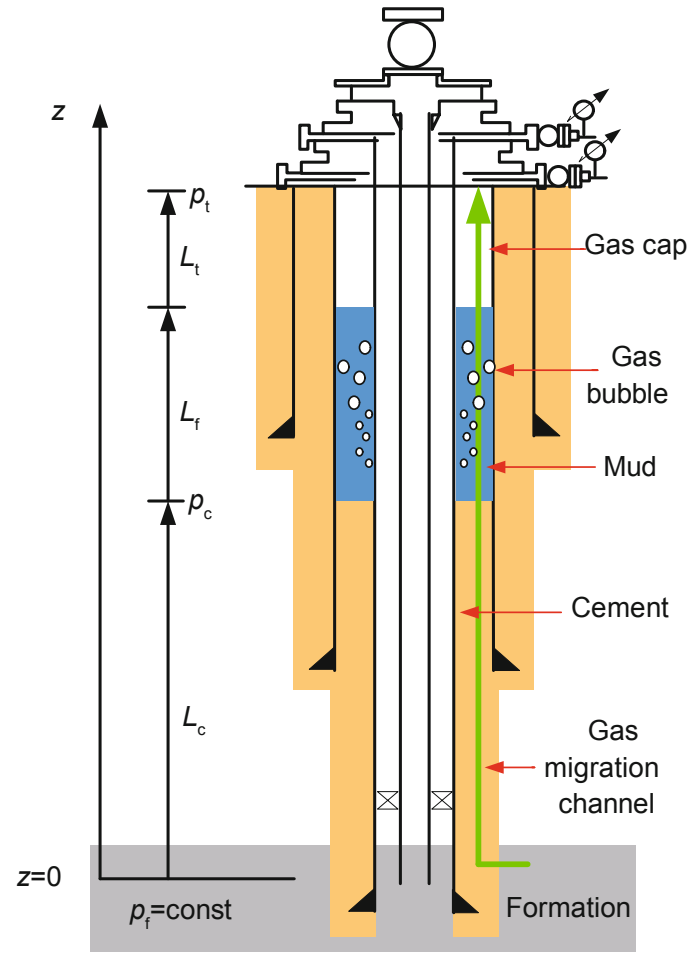

Fig. 12 Gas migration in a cement and mud column

pressure in the cement can be obtained as:

$\begin{cases}\frac{\partial^{2} p}{\partial z^{2}}+\frac{1}{p}\left(\frac{\partial p}{\partial z}\right)^{2}=\frac{1}{\zeta} \frac{\partial p}{\partial t} & \text { if } p<15 \mathrm{MPa} \text { and } z \leq L_{\mathrm{c}} \\ \frac{\partial^{2} p}{\partial z^{2}}=\frac{1}{\zeta} \frac{\partial p}{\partial t} & \text { if } p>15 \mathrm{MPa} \text { and } z \leq L_{\mathrm{c}}\end{cases}$

with

$$
\zeta=\frac{k}{\mu_{\mathrm{g}} \varphi c_{\mathrm{g}}}
$$

where $p$ is the pressure in the cement, $\mathrm{MPa} ; z$ is the distance from the gas-source formation, $\mathrm{m} ; t$ is time, $\mathrm{s} ; k$ is the cement permeability, $\mathrm{m}^{2} ; L_{\mathrm{c}}$ is the length of the cement column, $\mathrm{m} ; \mu_{\mathrm{g}}$ is the gas viscosity, $\mathrm{Pa} \cdot \mathrm{s} ; \varphi$ is the cement porosity, dimensionless; and $c_{\mathrm{g}}$ is the gas compressibility; $\mathrm{Pa}^{-1}$.

The boundary and initial conditions may be stated as follows:
a) $p=p_{\mathrm{c}}$ at $t=0$ for $z\left(0<z<L_{\mathrm{c}}\right)$
b) $p=p_{\mathrm{f}}$ at $z=0$ for all $t$
c) $\left.\frac{\partial p}{\partial z}\right|_{z=L_{\mathrm{c}}}=\frac{q_{\mathrm{g}} \mu_{\mathrm{g}}}{k A}$ for $t>0$

where $p_{\mathrm{c}}$ is the pressure on the top of the cement, $\mathrm{MPa} ; p_{\mathrm{f}}$ is the reservoir pressure, $\mathrm{MPa} ; q_{\mathrm{g}}$ is the gas flow rate, $\mathrm{m}^{3} / \mathrm{s}$; and $A$ is the wellbore area, $\mathrm{m}^{2}$.

\subsection{Gas migration in the stagnant mud}

Gas migration in the stagnant mud can be modeled as dispersed two-phase flow that can be described by a driftflux model (Xu and Wojtanowicz, 2003). Basic assumptions are a concentric annulus, equal phase pressure, uniform phase 
densities normal to the flow direction, constant temperature profile, and thermodynamic equilibrium. Due to slow phase segregation after the bleed-down, it is assumed that the relative velocity term is negligible. Under the assumptions, the one-dimensional two-equation drift-flux model is summarized in the following (Santos and Azar, 1997; Xu, 2002).

Continuity equations for the continuous (mud) and the dispersed phase (gas) are:

$$
\begin{aligned}
& \frac{\partial\left[(1-\alpha) \rho_{\mathrm{L}}\right]}{\partial t}+\frac{\partial\left[(1-\alpha) \rho_{\mathrm{L}} v_{\mathrm{L}}\right]}{\partial z}=0 \\
& \frac{\partial\left(\alpha \rho_{\mathrm{g}}\right)}{\partial t}+\frac{\partial\left(\alpha \rho_{\mathrm{g}} v_{\mathrm{g}}\right)}{\partial z}=0
\end{aligned}
$$

where $\alpha$ is the void fraction; $\rho_{\mathrm{g}}$ and $\rho_{\mathrm{L}}$ are the gas and liquid density, $\mathrm{kg} / \mathrm{m}^{3}$; and $v_{\mathrm{g}}$ and $v_{\mathrm{L}}$ are the gas and liquid velocity, $\mathrm{m} / \mathrm{s}$.

And mixture momentum equation is:

$$
\frac{\partial\left(\rho_{\mathrm{m}} v_{\mathrm{m}}\right)}{\partial t}+\frac{\partial\left(\rho_{\mathrm{m}} v_{\mathrm{m}}^{2}\right)}{\partial z}+\frac{\partial p}{\partial z}+\rho_{\mathrm{m}} g+\frac{f}{2 d_{\mathrm{h}}} \rho_{\mathrm{m}} v_{\mathrm{m}}^{2}=0
$$

with

$$
\begin{aligned}
& v_{\mathrm{g}}=v_{\mathrm{s}}+C_{0} v_{\mathrm{m}} \\
& v_{\mathrm{m}}=\left(q_{\mathrm{g}}+q_{\mathrm{L}}\right) / A=v_{\mathrm{sg}}+v_{\mathrm{sL}} \\
& d_{\mathrm{h}}=d_{\mathrm{o}}-d_{\mathrm{i}} \\
& \rho_{\mathrm{m}}=\rho_{\mathrm{g}} \alpha+\rho_{\mathrm{L}}(1-\alpha)
\end{aligned}
$$

where $\rho_{\mathrm{m}}$ and $v_{\mathrm{m}}$ are the mixture density $\left(\mathrm{kg} / \mathrm{m}^{3}\right)$ and velocity $(\mathrm{m} / \mathrm{s})$, respectively; $f$ is the friction factor; $C_{0}$ is the distribution factor; $d_{\mathrm{h}}$ is the hydraulic diameter of the annulus, $\mathrm{m} ; d_{\mathrm{i}}$ and $d_{\mathrm{o}}$ are the diameter of the inner string and the outer string, respectively, $\mathrm{m} ; v_{\mathrm{s}}$ is the gas slip velocity, $\mathrm{m} / \mathrm{s} ; v_{\mathrm{sg}}$ and $v_{\mathrm{sL}}$ are the superficial velocity of gas and liquid, respectively, $\mathrm{m} / \mathrm{s}$; and $q_{\mathrm{L}}$ is the liquid flow rate, $\mathrm{m}^{3} / \mathrm{s}$.

In order to complete the model, the slip velocity $\left(v_{\mathrm{s}}\right)$ and the fluid fraction factor $(f)$ must be algebraically specified. Based on analysis of the SCP field data, it can be safely assumed that the flow pattern in annulus is either bubble or slug flow. According to the Hasan and Kabir method (Hasan and Kabir, 1993), the value of the distribution factor $C_{0}$ for bubble flow can be described as:

$C_{0}=\left\{\begin{array}{lll}1.2 & \text { if } \quad d_{\mathrm{h}}<0.12 \mathrm{~m} & \text { or } \quad v_{\mathrm{sL}}>0.02 \mathrm{~m} / \mathrm{s} \\ 2.0 & \text { if } \quad d_{\mathrm{h}}>0.12 \mathrm{~m} & \text { and } \quad v_{\mathrm{sL}}<0.02 \mathrm{~m} / \mathrm{s}\end{array}\right.$

While for slug flow, $C_{0}$ is equal to 1.2.

For bubble flow, the slip velocity can be calculated as (Caetano et al, 1992):

$$
v_{\mathrm{s}}=1.53\left[\frac{\left(\rho_{\mathrm{L}}-\rho_{\mathrm{g}}\right) g \sigma}{\rho_{\mathrm{L}}^{2}}\right]^{1 / 4}(1-\alpha)^{1 / 2}
$$

where $\sigma$ is the surface tension of liquid, $\mathrm{N} / \mathrm{m}$.

And for slug flow in the vertical annulus, it is described as (Hasan and Kabir, 1992):

$$
v_{\mathrm{s}}=\left(0.345+\frac{0.1 d_{\mathrm{i}}}{d_{\mathrm{o}}}\right) \sqrt{\frac{g d_{\mathrm{o}}\left(\rho_{\mathrm{L}}-\rho_{\mathrm{g}}\right)}{\rho_{\mathrm{L}}}}
$$

Using the apparent Newtonian concept, equations for flow in Newtonian fluid can be used to calculate the Fanning friction factor. For laminar flow, the friction factor is:

$$
f=\frac{16}{R e_{\mathrm{m}}}
$$

with

$$
R e_{\mathrm{m}}=\frac{\rho_{\mathrm{m}} v_{\mathrm{m}} d_{\mathrm{h}}}{\mu_{\mathrm{m}}}
$$

where $\mu_{\mathrm{m}}$ is the mixture viscosity, $\mathrm{m} / \mathrm{s}$; and $R e_{\mathrm{m}}$ is the Reynolds number of two-phase flow.

The mixture viscosity for two-phase flow is:

$$
\mu_{\mathrm{m}}=\mu_{\mathrm{L}} \lambda_{\mathrm{L}}+\mu_{\mathrm{g}}\left(1-\lambda_{\mathrm{L}}\right)
$$

with

$$
\lambda_{\mathrm{L}}=\frac{A_{\mathrm{L}}}{A_{\mathrm{g}}+A_{\mathrm{L}}}
$$

where $\mu_{\mathrm{L}}$ is the mud viscosity, $\mathrm{Pa} \cdot \mathrm{s} ; \lambda_{\mathrm{L}}$ is the liquid holdup, dimensionless; and $A_{\mathrm{g}}$ and $A_{\mathrm{L}}$ are the flow areas occupied by gas and liquid respectively, $\mathrm{m}^{2}$.

For turbulent flow (Reynolds number is usually less than $10^{5}$ due to the high viscosity of mud), the friction factor is:

$$
f=\frac{0.3164}{R e_{\mathrm{m}}^{0.25}}
$$

Obtaining an analytical solution is generally not possible for most practical problems in two-phase flow. Numerical methods based on finite-difference concepts provide an alternate and powerful solution approach. The three equations, (3), (4) and (5) have been solved using the finite difference method with computational cells shown in Fig. 13, the semi-implicit pattern of which is as follows $(\mathrm{Xu}, 2002)$ :

$$
\begin{aligned}
& \frac{\left[(1-\alpha) \rho_{\mathrm{L}}\right]_{i}^{n+1}-\left[(1-\alpha) \rho_{\mathrm{L}}\right]_{i}^{n}}{\Delta t}+ \\
& \frac{\left[(1-\alpha) \rho_{\mathrm{L}}\right]_{i+1 / 2}^{n}\left(v_{\mathrm{L}}\right)_{i+1 / 2}^{n+1}-\left[(1-\alpha) \rho_{\mathrm{L}}\right]_{i-1 / 2}^{n}\left(v_{\mathrm{L}}\right)_{i-1 / 2}^{n+1}}{\Delta z}=0
\end{aligned}
$$

$$
\begin{aligned}
& \frac{\left(\alpha \rho_{\mathrm{g}}\right)_{i}^{n+1}-\left(\alpha \rho_{\mathrm{g}}\right)_{i}^{n}}{\Delta t}+ \\
& \frac{\left(\alpha \rho_{\mathrm{g}}\right)_{i+1 / 2}^{n}\left(v_{\mathrm{g}}\right)_{i+1 / 2}^{n+1}-\left(\alpha \rho_{\mathrm{g}}\right)_{i-1 / 2}^{n}\left(v_{\mathrm{g}}\right)_{i-1 / 2}^{n+1}}{\Delta z}=0
\end{aligned}
$$




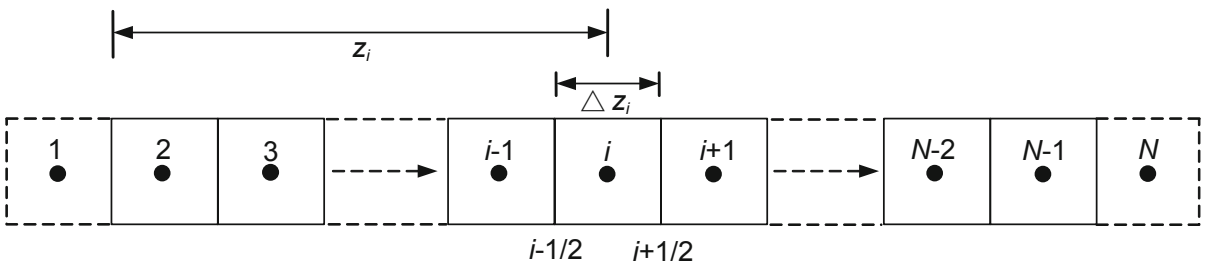

Fig. 13 Computational cells for finite difference solution

$$
\begin{aligned}
& \frac{\left(\rho_{\mathrm{m}} v_{\mathrm{m}}\right)_{i}^{n+1}-\left(\rho_{\mathrm{m}} v_{\mathrm{m}}\right)_{i}^{n}}{\Delta t}+\frac{\left(\rho_{\mathrm{m}} v_{\mathrm{m}}{ }^{2}\right)_{i+1 / 2}^{n}-\left(\rho_{\mathrm{m}} v_{\mathrm{m}}^{2}\right)_{i-1 / 2}^{n}}{\Delta z}+ \\
& \frac{p_{i+1 / 2}^{n+1}-p_{i-1 / 2}^{n+1}}{\Delta z}+\left(\rho_{\mathrm{m}} g\right)^{n}+\left(\frac{f}{2 d_{\mathrm{h}}} \rho_{\mathrm{m}} v_{\mathrm{m}}^{2}\right)^{n}=0
\end{aligned}
$$

\subsection{Gas unloading and accumulation at the wellhead}

At the wellhead, gas is released from the top when the needle valve is open. While in SCP buildup, gas accumulates at the top with the closed needle valve. Thus, two different upper boundary conditions are considered.

Gas or gas-liquid flowing through the needle valve to the atmosphere can be considered as single-phase gas or multiphase flow through a choke (Perkins, 1993). During bleed-down, gas usually flows at choked velocity and its flow rate is easy to record. If the gas flow rate cannot be measured directly, it can be computed from the following iterative procedure.

a) Initial guess that the critical pressure ratio $y_{\mathrm{c}}{ }^{*}=0.5$, then calculate the pressure ratio $y=p_{2} / p_{1}$, where $p_{2}$ is the downstream pressure (atmospheric pressure), and $p_{1}$ is the upstream pressure.

b) If $y<y_{\mathrm{c}}{ }^{*}$, critical flow exists. Calculate the gas flow rate using the following equation (Gilbert, 1954).

$$
q_{\mathrm{gm}}=738.9 \times\left(\frac{p_{1} d_{\mathrm{ch}}^{1.89}}{q_{\mathrm{Lm}}^{0.454}}\right)^{1.83}
$$

where $d_{\text {ch }}$ is the diameter of the choke, $\mathrm{m}$; and $q_{\mathrm{Lm}}$ is the liquid flow rate $\left(\mathrm{m}^{3} / \mathrm{s}\right)$ which can be calculated by the volume of liquid collected and the bleed-down time recorded in SCP diagnostic tests.

If not, sub-critical flow exists. The gas flow rate is:

$$
q_{\mathrm{gm}}=0.02 \times \frac{\pi}{4} d_{\mathrm{ch}}^{2} \sqrt{\frac{p_{1}-p_{2}}{\rho_{\mathrm{m} 1}}}-q_{\mathrm{Lm}}
$$

where $\rho_{\mathrm{m} 1}$ is the mixture density at $p_{1}, \mathrm{~kg} / \mathrm{m}^{3}$.

c) Calculate the gas/liquid ratio $R_{1}$ (Ashford and Pierce, $1975)$ and $y_{\mathrm{c}}$, which is obtained from the following equation.

$$
\begin{aligned}
& \gamma R_{1}^{2}\left(\frac{\gamma+1}{\gamma-1}\right) y_{\mathrm{c}}^{\frac{\gamma-1}{\gamma}}+2 R_{1}(\gamma+1) y_{\mathrm{c}}+\gamma y_{\mathrm{c}}^{\frac{\gamma+1}{\gamma}}- \\
& 2 R_{1}-2 R_{1}^{2} \frac{\gamma}{\gamma-1}=0
\end{aligned}
$$

where $\gamma$ is the ratio of specific heats, dimensionless.

Then set $y_{\mathrm{c}}{ }^{*}=y_{\mathrm{c}}$.

d) Repeat step b) to c) until there is no change in the flow condition.

The gas chamber in the wellhead is treated separately from all other cells, which are completely filled with gas. When the needle valve is closed, it does not lose gas to any other cell but receives gas from the cell immediately below it. The volume of this gas chamber changes with time, at $n+1$ time step, which is related to the $n$-th step volume (Xu, 2002), in the following manner:

$$
\begin{aligned}
& V_{\mathrm{wh}}^{n+1}=V_{\mathrm{wh}}^{n}+ \\
& \Delta\left[\sum_{j=1}^{N-1}\left(V_{\mathrm{g}}\right)_{j}\right]-\Delta\left[\sum_{j=1}^{N}\left(V_{\mathrm{L}}\right)_{j}\right]-\left(q_{\mathrm{g}}\right)_{0}^{n+1} \Delta t+\left(q_{\mathrm{gm}}\right)_{N}^{n+1} \Delta t
\end{aligned}
$$

where $N$ is the number of equal-size cells in the well; $V_{\text {wh }}$ is the volume of gas chamber, $\mathrm{m}^{3} ; V_{\mathrm{g}}$ and $V_{\mathrm{L}}$ are the volumes of gas and liquid respectively, $\mathrm{m}^{3}$; and $q_{\mathrm{gm}}$ is the gas flow rate from the choke, $\mathrm{m}^{3} / \mathrm{s}$.

The second term on the right side of the equation is the volume of gas accumulated in the remaining mud column. The following term is the volume increase caused by increased liquid column pressure during this time step. The second to last term is the volume reduction due to gas flow from the cement below the liquid column. The last term indicates the increased volume caused by gas flow out from the annulus during the bleed-down, which is zero during casing pressure buildup.

The wellhead pressure at $n+1$ time step is:

$$
p_{\mathrm{wh}}^{n+1}=\frac{p_{\mathrm{wh}}^{n} n^{\prime n+1} V_{\mathrm{wh}}^{n} Z^{n+1}}{n^{\prime n} V_{\mathrm{wh}}^{n+1} Z^{n}}
$$

where $p_{\mathrm{wh}}$ is the wellhead pressure, MPa; $Z$ is gas-law deviation factor, and $n^{\prime}$ is the moles of gas.

Once the volume of the gas chamber is estimated by Eq. (24), the wellhead pressure can be calculated from Eq. (25). This step, in turn, allows calculation of interface pressure from the wellhead pressure from Eq. (20).

\subsection{Coupled gas flows in cement and mud}

The most important problem for coupling gas flow in the cement and the mud is calculating the interface pressure. The calculation procedure is iterative, which involves a simultaneous solution of the mass and momentum equations for pressure and velocity in all cells in the mud column except for the gas chamber.

The coupling procedure is shown in Fig. 14 ( Xu and 
Wojtanowicz, 2003), which begins with the pressure bleeddown because the SCP diagnostic test begins with it. At initial time, the wellhead pressure, size of the gas chamber and the gas concentration in the mud column are known. A constant pressure gradient throughout the entire mud column and zero flow-rate at the interface between cement and mud were assumed. Then the pressure and gas distribution in the mud as well as pressure at the interface can be calculated. Assuming the cement is filled with gas, the pressure is uniform and equal to the interface pressure in the entire cement, except at the point of the gas-source formation.

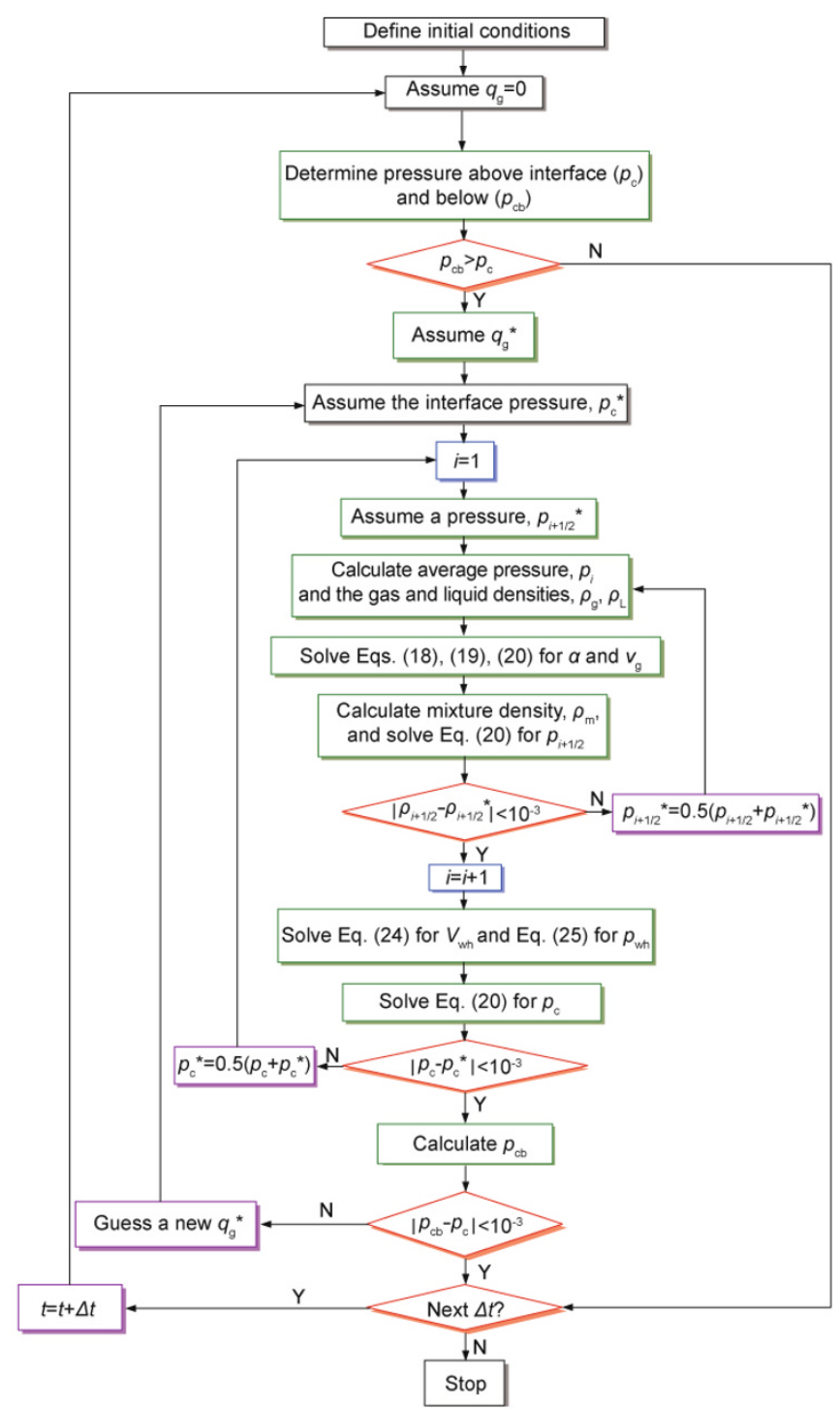

Fig. 14 Solution procedure for gas flow in mud and cement

The gas flow rate at each recorded time interval was determined from the bleed-down pressure history. With initial condition and two boundary conditions (known flow rate at the wellhead and constant formation pressure), the pressure distribution in the mud can be calculated by the iterative procedure. The pressure distribution in the cement can be calculated by Eq. (1). Iteration stops when the flow rate and pressure at either side of the interface are equal.

When a good match for bleed-down is obtained, the initial condition at the instant of shut-in is known. The buildup just right begins with the variable distribution at the end of bleeddown. Assuming zero flow-rate at the interface, the pressure distribution in mud and cement can be calculated. If there is a pressure difference across the interface, a force will drive gas flowing through the interface. Therefore, the pressure distribution should be recalculated using a assumed flow rate. The computation is repeated until pressure at each side of the interface is equal. Time is then incremented, the boundary conditions defined again, and the process is repeated until the desired time is reached.

\section{Illustration}

The mathematic model was verified with selected data from one gas well in Xinjiang Uygur Autonomous Region, China. The geological conditions, wellbore structure, and cement data of this well are shown in Fig. 15. And information about gas, mud, cement and formation are listed in Table 2 .

Table 2 Information of the illustration wel

\begin{tabular}{ccc}
\hline Category & Property & Value \\
\hline \multirow{2}{*}{ Gas } & Viscosity, Pa $\cdot \mathrm{s}$ & $10^{-5}$ \\
& Compressibility, $\mathrm{Pa}^{-1}$ & $1.112 \times 10^{-7}$ \\
& Specific gravity & 0.7 \\
\hline \multirow{2}{*}{ Mud } & Viscosity, Pa $\cdot \mathrm{s}$ & 0.056 \\
& Interface tension, $\mathrm{N} / \mathrm{m}$ & 0.068 \\
& Density, $\mathrm{kg} / \mathrm{m}^{3}$ & 2270 \\
\hline \multirow{2}{*}{ Cement } & Permeability, $\mathrm{m}^{2}$ & $1.8 \times 10^{-14}$ \\
& Porosity & 0.01 \\
\hline Formation & Pressure, $\mathrm{MPa}$ & 46 \\
\hline
\end{tabular}

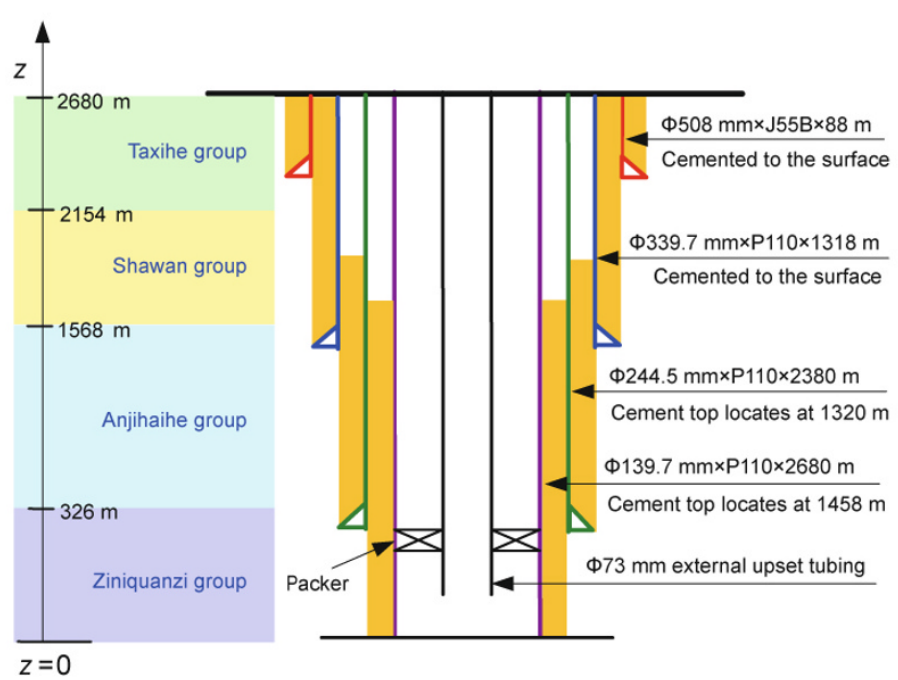

Fig. 15 Structural parameters of the well

The casing pressure of the $\mathrm{B}$ annulus in the illustration well has been calculated from the coupled model. The annulus between the $139.7 \mathrm{~mm}$ production casing and the 
$244.5 \mathrm{~mm}$ intermediate casing was bled for 12 minutes before the needle valve was closed and the following casing buildup measurement lasted 24 hours. As shown from Fig. 16, the calculation result coincides well with the actual data, which presents a long bleed-down and normal buildup pattern.

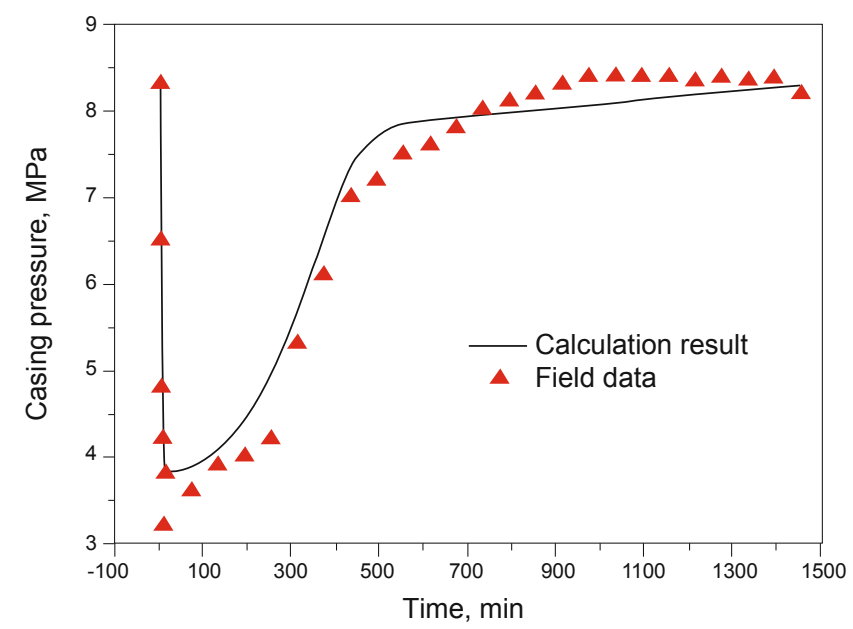

Fig. 16 Calculation result of the casing pressure in the illustration well

\section{Conclusions}

Five patterns of SCP bleed-down and buildup were summarized from the field data. The possible mechanisms leading to SCP have been analyzed, which include thermal expansion, tubular mechanical failures, and gas migration. Then possible reasons for SCP in different annulus have also been indicated. On this basis, a coupled mathematical model of gas migration in a cemented annulus with a mud column has been developed based on annular percolation and gasliquid two-phase flow theories. Finally, the mathematical model was verified with selected data from one actual gas well.

\section{Acknowledgments}

Research work was co-financed by the China National Natural Science Foundation and Shanghai Baosteel Group Corporation (No. 51074135), Program for New Century Excellent Talents in University (No. NCET-08-0907) and Jilin Oilfield Company Project (No. JS10-W-14-JZ-32-51). Without their support, this work would not have been possible.

\section{References}

Anders J, Rossberg S, Dube H, et al. Well integrity operations at Prudhoe Bay, Alaska. Paper SPE 102524 presented at the 2006 SPE Annual Technical Conference and Exhibition, 24-27 September, 2006, San Antonio, Texas

Ashford F E and Pierce P E. Determining multiphase pressure drops and flow capacities in downhole safety valves. Journal of Petroleum Technology. 1975. 27(9): 1145-1152

Bourgoyne A T Jr, Scott S L and Manowski W. A review of sustained casing pressure (SCP) occurring on the OSC. Paper presented at the
LSU/MMS Well Control Workshop held on 1 April, 1998

Bourgoyne A T Jr, Scott S L and Regg J B. Sustained casing pressure in offshore producing wells. Paper OTC 11029 presented at Offshore Technology Conference, 3-6 May, 1999, Houston, Texas

Caetano E F, Shoham O and Brill J P. Upward vertical two-phase flow through an annulus, Part I: Single-phase friction factor, Taylor bubble rise velocity and flow pattern prediction. Journal of Energy Resources Technology. 1992. 114(1): 1-13

Duan S and Wojtanowicz A K. Risk analysis method of continuous air emissions from wells with sustained casinghead pressure. Paper SPE 94455-STU presented at the 2005 SPE/EPA/DOE Exploration and Production Environmental Conference, 7-9 March, 2005, Galveston, Texas

Dusseault M B, Gray M N and Nawrocki P A. Why oilwells leak: Cement behavior and long-term consequences. Paper SPE 64733 presented at SPE International Oil and Gas Conference and Exhibition, 7-10 November, 2000, Beijing, China

Gilbert W E. Flowing and gas-lift well performance. API Drilling and Production Practice. 1954: 126-157 (Paper API 54-126)

Hasan A R and Kabir C S. Two-phase flow in vertical and inclined annuli. International Journal of Multiphase Flow. 1992. 18(2): 279293

Hasan A R and Kabir C S. A mechanistic approach to understanding wellbore phase redistribution. Paper SPE 26483 presented at the 68th Annual Technical Conference and Exhibition of the Society of Petroleum Engineers, 3-6 October, 1993, Houston, Texas

Kinik K and Wojtanowicz A K. Identifying environmental risk of sustained casing pressure. Paper SPE 143713 presented at the SPE Americas E\&P Health, Safety, Security and Environmental Conference, 21-23 March, 2011, Houston, Texas

Milanovic D and Smith L. A case history of sustainable annulus pressure in sour wells: Prevention, evaluation and remediation. Paper SPE 97597 presented at the SPE ATW HPHT Sour Well Design Conference, 17-19 May, 2005, Woodlands, Texas

Nishikawa S. Mechanism of gas migration after cement placement and control of sustained casing pressure. Master Thesis. Louisiana State University. 1999

Nishikawa S and Wojtanowicz A K. Experimental assessment of the bleed-and-lube method for removal of sustained casing pressure. Paper SPE 2001-041 presented at Petroleum Society's Canadian International Petroleum Conference, 12-14 June, 2001, Calgary, Alberta

Perkins T K. Critical and subcritical flow of multiphase mixtures through chokes. SPE Drilling \& Completion. 1993. 8(4): 271-276 (Paper SPE 20633)

Santos O L A and Azar J J. A study on gas migration in stagnant nonNewtonian fluids. Paper SPE 39019 presented at Latin American and Caribbean Petroleum Engineering Conference and Exhibition, 30 August-3 September, 1997, Rio de Janeiro, Brazil

Wojtanowicz A K, Nishikawa S and Xu R. Diagnosis and remediation of sustained casing pressure in wells. Final report submitted to US Department of Interior Minerals Management Service, 31 July, 2001

$\mathrm{Xu}$ R. Analysis of diagnostic testing of sustained casing pressure in wells. Doctoral Thesis. Louisiana State University. 2002

$\mathrm{Xu} \mathrm{R}$ and Wojtanowicz A K. Diagnosis of sustained casing pressure from bleed-off/buildup testing patterns. Paper SPE 67194 presented at SPE Production and Operations Symposium, 24-27 March, 2001, Oklahoma City, Oklahoma

$\mathrm{Xu}$ R and Wojtanowicz A K. Diagnostic testing of wells with sustained casing pressure: An analytical approach. Paper SPE 2003-221 presented at Petroleum Society's Canadian International Petroleum Conference, 10-12 June, 2003, Calgary, Alberta

(Edited by Sun Yanhua) 